\title{
Case Report \\ Detection and quantification of Legionella pneumophila DNA in serum: case reports and review of the literature
}

Correspondence

Bram M. W. Diederen

bramdiederen@gmail.com

Received 6 December 2005

Accepted 5 January 2006

\author{
Bram M. W. Diederen, ${ }^{1}$ Caroline M. A. de Jong, ${ }^{1}$ Jan A. J. W. Kluytmans, ${ }^{2}$ \\ Anneke van der Zee ${ }^{1}$ and Marcel F. Peeters ${ }^{1}$ \\ ${ }^{1}$ Laboratory of Medical Microbiology and Immunology, St Elisabeth Hospital, PO Box 747, \\ 5000 AS Tilburg, The Netherlands \\ ${ }^{2}$ Laboratory of Microbiology and Infection Control, Amphia Hospital, PO Box 90158, 4800 RK \\ Breda, The Netherlands
}

\begin{abstract}
Legionella pneumonia can be difficult to diagnose. Existing laboratory tests all have shortcomings, especially the ability to diagnose all Legionella spp. at an early stage. Detection of Legionella DNA in serum can be a valuable tool for the diagnosis of Legionnaires' disease (LD). This report describes two patients with LD diagnosed by PCR using serum samples. In addition, quantification of $L$. pneumophila DNA using real-time PCR during the course of illness was carried out. The results obtained mirrored both the clinical condition and $\mathrm{C}$-reactive protein values during the course of the illness. Quantification of Legionella DNA in serum using real-time PCR could be a valuable tool to monitor the effects of antimicrobial therapy in patients with LD.
\end{abstract}

\section{Introduction}

Legionnaires' disease (LD) is an acute pneumonia caused by Legionella spp. These Gram-negative bacilli are ubiquitous in both man-made and natural aquatic reservoirs. Although currently more than 48 Legionella spp. have been described, more than $90 \%$ of culture-confirmed clinical cases are caused by Legionella pneumophila (Yu et al., 2002). Legionella spp. are responsible for $1-5 \%$ of cases of communityacquired pneumonia (CAP) (Breiman \& Butler, 1998). Clinically and radiographically, LD cannot be distinguished from pneumonia caused by other microbial pathogens. Because of the high mortality rate in patients with LD requiring hospitalization, early diagnosis to enable adequate antimicrobial treatment is potentially life-saving (Fields et al., 2002). Diagnosis of LD can be quite difficult and is based on phenotypic (culture, serological testing and antigen detection in urine) and genotypic (PCR) methods. Isolation of Legionella from respiratory secretions is considered to be the gold standard in case definition, but is not very sensitive (10-80\% sensitivity), and a positive result is not available until at least 3 days after incubation. Another major limitation of sputum culture is that $<50 \%$ of patients with LD produce sputum (Murdoch, 2003). Serological testing has a high sensitivity and a high specificity, but is of limited clinical value, as it may take up to 9 weeks for patients to develop detectable antibodies. For the detection of L. pneumophila serogroup 1, urinary antigen tests have sensitivities in the

Abbreviations: CAP, community-acquired pneumonia; CRP, C-reactive protein; ICU, intensive care unit; LD, Legionnaires' disease. range of $70-100 \%$ and specificities approaching $100 \%$, but these assays only detect $L$. pneumophila serogroup 1 reliably (Murdoch, 2003; Yzerman et al., 2002). Genotypic methods utilize PCR to detect the presence of Legionellaspecific DNA in respiratory secretions, urine and serum, and show varying degrees of sensitivity and specificity (Murdoch, 2003). Diagnostic PCR assays have principally targeted specific regions within 16S (Hayden et al., 2001; Cloud et al., 2000) and 5S (Lindsay et al., 2004) rRNA genes and the macrophage inhibitor potentiator (mip) gene (Ballard et al., 2000; Lindsay et al., 1994). PCR techniques have the potential to provide a rapid diagnosis of $\mathrm{LD}$ with the use of readily obtainable specimens such as serum and urine (Lindsay et al., 2004; Matsiota-Bernard et al., 2000; Murdoch et al., 1996).

In this report, we describe two patients with LD diagnosed using Legionella-specific real-time PCR on serum samples. In addition, a serial quantification of L. pneumophila DNA during the course of the illness was carried out. To our knowledge, this is the first time that the sequel of quantifying L. pneumophila DNA during LD has been described.

\section{Case 1}

In September 2005, a 67-year-old white male was admitted to the pulmonology department of the Amphia Hospital, Breda, The Netherlands, with a history of malaise, cough, fever and shortness of breath. He was a smoker with a mean consumption of 20 cigarettes per day. He did not take any medication and had not travelled recently. Vital signs on 
arrival included a blood pressure of $155 / 85 \mathrm{~mm} \mathrm{Hg}$, a heart rate of 117 beats $\mathrm{min}^{-1}$, a respiratory rate of $30 \mathrm{~min}^{-1}$ and a temperature of $40 \cdot 7^{\circ} \mathrm{C}$. Examination of the chest revealed decreased breath sounds and crackles in the right lung base, and a chest radiograph showed extensive consolidation of the right lung. A complete blood count revealed a white blood cell count of 12300 cells $\mu \mathrm{l}^{-1}$ and a C-reactive protein (CRP) value of $535 \mathrm{mg} \mathrm{l}^{-1}$. Antibiotic therapy with oral amoxycillin/clavulanic acid (625 mg every $8 \mathrm{~h}$ ), started by his general practitioner, was changed to intravenous amoxycillin/clavulanic acid (1000/200 mg q.i.d.) plus erythromycin (1000 mg q.i.d.). Bacterial cultures for bacteria and fungi (sputum and blood) remained negative. Two days after admission, his condition deteriorated and he was transferred to the intensive care unit (ICU) where he underwent intubation as a result of hypoxia and respiratory distress.

One day after admission at the ICU (day 2), a sputum and a serum sample were tested for Legionella using real-time PCR. The serum $(200 \mu \mathrm{l})$ was processed with the MagNA Pure Total Nucleic Acid kit (Roche Diagnostics). For the detection of Legionella in serum samples, an assay was used targeted at specific regions within the 5S rRNA gene (Lindsay et al., 2004) and detected in real-time using a TaqMan probe, Leg5S [6-carboxyfluorescein (FAM)5'-CCGCGCCAATGATAGTGTGAGGC-3'-6-carboxytetramethylrhodamine (TAMRA)]. Real-time PCR was performed on an AbiPrism 7900HT Sequence Detection System (Applied Biosystems). DNA was amplified according to the following parameters: after incubation for $2 \mathrm{~min}$ at $50^{\circ} \mathrm{C}$ and denaturation for $10 \mathrm{~min}$ at $95^{\circ} \mathrm{C}$, amplification consisted of 50 cycles of denaturation for $15 \mathrm{~s}$ at $95^{\circ} \mathrm{C}$ and $1 \mathrm{~min}$ of annealing and extension at $65^{\circ} \mathrm{C}$. Random serum samples from two healthy volunteers were included as negative controls after every four samples. In each run, a no-template negative control was added. Sensitivity controls consisted of tenfold dilutions of L. pneumophila DNA ranging from 1000 to $10 \mathrm{fg}$. As an internal control, Phocid herpesvirus 1 was added to the samples to monitor processing as well as PCR inhibition (Diederen et al., 2005a).

Both samples (sputum and serum) tested positive for Legionella. In addition, an immunochromatographic membrane test (Binax NOW; Binax) to detect L. pneumophila serogroup 1 soluble antigens in urine was positive. Culture was carried out as follows: samples were plated on buffered charcoal yeast extract (BCYE) agar (Oxoid) and on BCYE agar with cefamandole, polymyxin and anisomycin (Oxoid). Legionella-specific media were incubated for 10 days at $35^{\circ} \mathrm{C}$ in a humidified atmosphere. Colonies that grew on BCYE agar but failed to grow on blood agar were expected to be Legionella spp. Further identification was carried out by determination of the L. pneumophila serogroups using a slide agglutination test (Dryspot Legionella Latex Test; Oxoid). A lower respiratory tract sample (bronchoalveolar lavage) produced L. pneumophila serogroup 1 . We collected consecutive serum samples to quantify $L$. pneumophila using a Legionella-specific PCR. The threshold cycle value $(\mathrm{Ct})$ is inversely proportional to the log of the amount of target DNA initially present and was calculated by using SDS software version 2.0 (Applied Biosystems). The results of Legionella-specific real-time PCR during the course of the illness are outlined in Fig. 1. Antibiotic therapy was changed to ciprofloxacin ( $400 \mathrm{mg}$ b.i.d.) plus erythromycin (1000 mg q.i.d.) on day 3 after admission to the ICU. His clinical condition, however, did not improve significantly in the first days after ICU admission. Despite appropriate treatment, he remained critically ill with unstable systemic blood pressure and development of renal failure. Ct values mirrored the clinical condition and CRP values during the course of illness; for the first 4 days, Ct values were stable at $\sim 29$ in Legionella real-time PCR. On the fifth day after admission to the ICU department, the patient's condition stabilized, but on day 6 he deteriorated again and became haemodynamically unstable, despite inotropic drug support with serum urea and creatinine at $23.6 \mathrm{mmol} \mathrm{l}^{-1}$ (reference values $2 \cdot 9-7 \cdot 5 \mathrm{mmol} \mathrm{l}^{-1}$ ) and $539 \mu \mathrm{mol} \mathrm{l}^{-1}$ (reference values 55-95 $\left.\mu \mathrm{mol} \mathrm{l}^{-1}\right)$, respectively. This severe deterioration

(a)

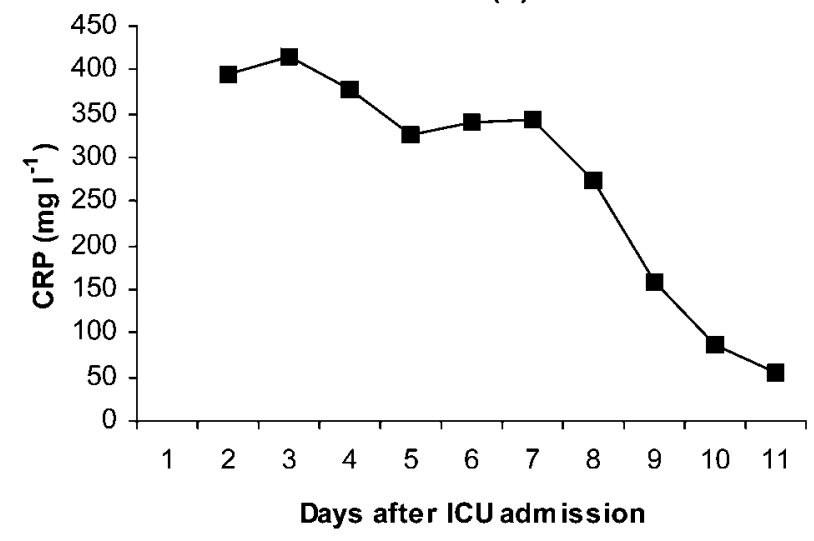

(b)

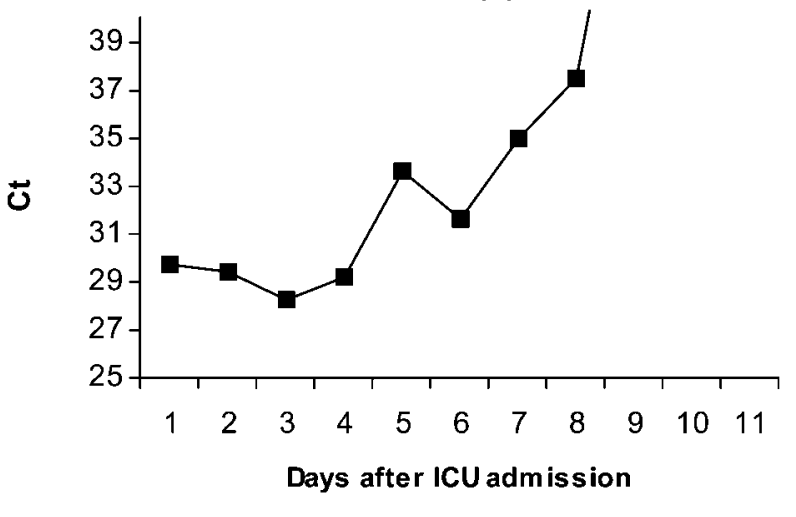

Fig. 1. Results of CRP measurements (a) and real-time Legionella PCR (b) of serum from patient 1. The threshold cycle value (Ct) is inversely proportional to the log of the amount of target DNA initially present and was calculated by using SDS software version 2.0 (Applied Biosystems). 
coincided with a decrease in Ct (an increase in bacterial load) on day 6. In addition to the haemodynamic support, rifampicin (600 mg b.i.d.) and activated protein C (Xigris) were added. The patient showed a remarkable improvement during the following days and arterial oxygenation improved with radiographic resolution of infiltrates. Ct values increased during the following days and all samples tested after day 8 were negative in Legionella-specific real-time PCR. Two weeks after admission to the ICU, he was transferred to the medium-care department.

\section{Case 2}

A 42-year-old white male was admitted to the pulmunology department of the St Elisabeth Hospital, Tilburg, The Netherlands, with a history of cough, shortness of breath and mental confusion in October 2005. He smoked 25 cigarettes per day. Vital signs on arrival included blood pressure of $140 / 80 \mathrm{~mm} \mathrm{Hg}$ and a temperature of $37 \cdot 6^{\circ} \mathrm{C}$. Examination of the chest revealed crackles in the left lung base and a chest radiograph showed consolidation of the left lung base. A complete blood count showed a white blood cell count of 6800 cells $\mu^{-1}$ and a CRP value of $315 \mathrm{mg} \mathrm{l}^{-1}$. Antibiotic therapy with oral ofloxacin ( $400 \mathrm{mg}$ b.i.d.) was started. A serum sample taken on the first day after admission tested positive in real-time PCR for Legionella with a Ct of 30. An immunochromatographic membrane test (Binax NOW; Binax) to detect L. pneumophila serogroup 1 soluble antigens in urine was positive. Pleural fluid obtained on day 3 after admission was cultured on Legionella-specific media and produced L. pneumophila serogroup 1 . The patient responded after initiating therapy with ofloxacin; his condition gradually improved and CRP values dropped from $227 \mathrm{mg} \mathrm{l}^{-1}$ on day 2 to 70 on day 7 . The results of Legionella-specific real-time PCR showed an almost linear increase in Ct values (indicating a logarithmic decrease in bacterial DNA) over the time course of infection (Fig. 2) and mirrored the clinical condition and CRP values during the acute stage of infection. The patient was discharged home 14 days after admission.

\section{Discussion}

The main disadvantage of testing sputum samples is that $<50 \%$ of patients with LD produce sputum. This has prompted investigation of the use of PCR for testing other sample types. The first report on the detection of Legionella DNA in serum was by Lindsay et al. (1994) using a conventional mip gene-based PCR assay using Southern blotting with a Legionella-specific probe. All patients with confirmed LD (five in total) tested positive in the acute and convalescent sera. This study included one convalescent serum sample that was positive for Legionella DNA 37 days after the onset of the patient's symptoms. Murdoch et al. (1996) tested urine and serum samples from 28 patients with LD and 24 patients with pneumonia due to organisms other than Legionella spp. The majority of patients in this study were infected with organisms other than L. pneumophila (a)

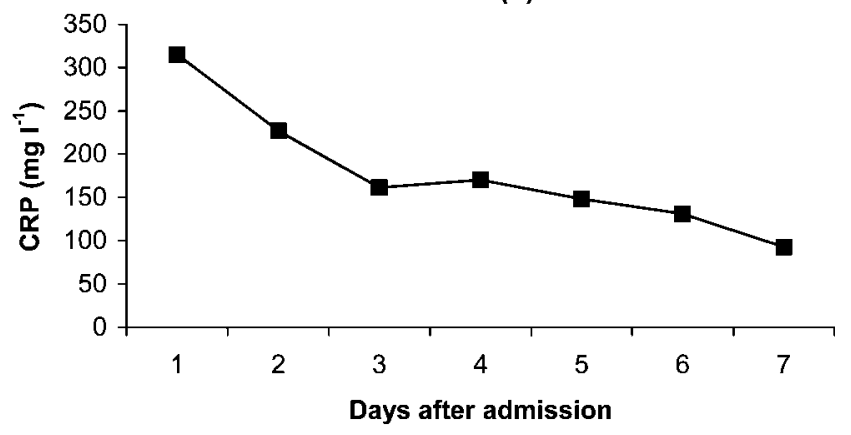

(b)

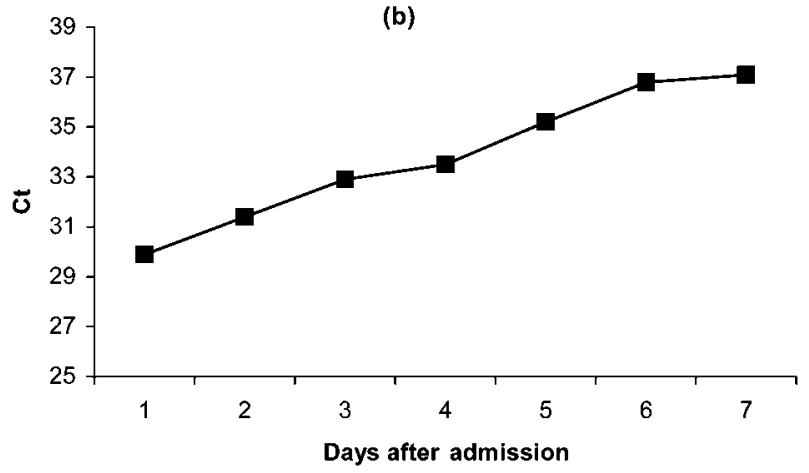

Fig. 2. Results of CRP measurements (a) and real-time Legionella PCR (b) of serum from patient 2. The threshold cycle value $(\mathrm{Ct})$ is inversely proportional to the log of the amount of target DNA initially present and was calculated by using SDS software version 2.0 (Applied Biosystems).

serogroup 1. Legionella DNA was detected in serum samples in 12 of 28 patients ( $43 \%$ ) with LD using a conventional 5S rRNA gene-based PCR assay. If used at the time of specimen collection, PCR of both urine and serum combined would have detected an additional 11 cases in the acute phase of disease. Legionella DNA was not detected in samples from the control patients. In another report, Murdoch et al. (1999) used a guinea pig model and detected Legionella DNA in $55 \%$ of leukocyte samples and $28 \%$ of urine samples. The sensitivity of the PCR was highest for samples collected within 3 days of inoculation. Matsiota-Bernard et al. (2000) detected L. pneumophila DNA in 12 serum samples from 41 patients with LD (29\%) and no Legionella DNA in 10 patients with pneumonia due to organisms other than Legionella. In a recent report, a Legionella-specific $5 \mathrm{~S}$ rRNA gene PCR on patient serum was positive in $80.5 \%$ of cases (54/67 patients), with a peak positivity at 6-10 days after disease onset (Lindsay et al., 2004). This peak corresponded to the urinary antigen peak, suggesting that circulating DNA coincides with the urinary antigen filtered from the blood by the kidneys. Unlike urinary antigen, the number of PCR positives decreased very slowly, perhaps as a result of the slow release of DNA from Legionella spp. surviving in macrophages. Murdoch \& Chambers (2000) 
described the use of PCR in a patient with CAP caused by Legionella dumoffii in New Zealand. Legionella DNA was detected in serial peripheral leukocytes, serum and urine samples when first collected. Buffy coat and urine samples remained positive for up to 56 days after the onset of symptoms, whereas serum samples were positive from 10 to 16 days after the onset of symptoms.

In New Zealand and Australia, there have been multiple cases of Legionella longbeachae CAP associated with exposure to soil and $L$. longbeachae is now recognized as the second most common cause of legionellosis (Cameron et al., 1991; Steele et al., 1990). Although CAP due to Legionella nonpneumophila spp. is rare in other parts of world, when specifically sought, unsuspected community-acquired infections may be uncovered. Recently, we described a patient who developed CAP due to L. longbeachae diagnosed with PCR analysis of sputum and serum (Diederen et al., 2005b). We concluded that, since most laboratory tests for Legionella cannot detect infections caused by Legionella nonpneumophila spp., culture on Legionella-selective media or PCR should be considered when diagnosing severe pneumonia in patients with an unknown aetiology.

The decision to order diagnostic tests for Legionella infection is usually limited to at-risk patients or patients with severe pneumonia and should consist of a urinary antigen test combined, if available, with Legionella PCR on sputum and serum. This is, in our view, the best initial testing strategy that will detect all Legionella spp. and provide results within a time frame that will affect clinical management. Here, we describe two patients with LD diagnosed using Legionella-specific real-time PCR on serum samples. The association between disease progression and viral load is well established for infections with a number of viruses, particularly human immunodeficiency virus, hepatitis $\mathrm{B}$ virus and hepatitis C virus (Hodinka, 1998). This is the first study in which real-time PCR has been used to monitor L. pneumophila DNA longitudinally in patients with LD. Detection of Legionella DNA in serum may reflect changes in bacterial load over time and may allow the assessment of the response of the patient to treatment. Further investigation of PCR-based diagnosis using serum samples is needed to establish its role in diagnosis and monitoring of patients with LD.

\section{References}

Ballard, A. L., Fry, N. K., Chan, L., Surman, S. B., Lee, J. V., Harrison, T. G. \& Towner, K. J. (2000). Detection of Legionella pneumophila using a real-time PCR hybridization assay. J Clin Microbiol 38, 4215-4218.

Breiman, F. R. \& Butler, J. C. (1998). Legionnaires' disease: clinical, epidemiological, and public health perspectives. Semin Respir Infect 13, 84-89.

Cameron, S., Roder, D., Walker, C. \& Feldheim, J. (1991). Epidemiological characteristics of Legionella infection in South Australia: implications for disease control. Aust N Z J Med 21, 65-70.
Cloud, J. L., Carroll, K. C., Pixton, P., Erali, M. \& Hillyard, D. R. (2000). Detection of Legionella species in respiratory specimens using PCR with sequencing confirmation. J Clin Microbiol 38, 1709-1712.

Diederen, B. M. W., de Jong, C. M. A., Aarts, I., Peeters, M. F., van Gageldonk-Lafeber, A. B., Wilbrink, B. \& van der Zee, A. (2005a). No evidence of Legionella infection in general practice patients presenting with acute respiratory infections in The Netherlands. Clin Microbiol Infect 11, 410-412.

Diederen, B. M. W., van Zwet, A. A., van der Zee, A. \& Peeters, M. F. (2005b). Community-acquired pneumonia caused by Legionella longbeachae in an immunocompetent patient. Eur J Clin Microbiol Infect Dis 24, 545-548.

Fields, B. S., Benson, R. F. \& Besser, R. E. (2002). Legionella and Legionnaires' disease: 25 years of investigation. Clin Microbiol Rev 15, 506-526.

Hayden, R. T., Uhl, J. R., Qian, X., Hopkins, M. K., Aubry, M. C., Limper, A. H., Lloyd, R. V. \& Cockerill, F. R. (2001). Direct detection of Legionella species from bronchoalveolar lavage and open lung biopsy specimens: comparison of LightCycler PCR, in situ hybridization, direct fluorescence antigen detection and culture. J Clin Microbiol 39, 2618-2626.

Hodinka, R. L. (1998). The clinical utility of viral quantitation using molecular methods. Clin Diagn Virol 10, 25-47.

Lindsay, D. S., Abraham, W. H. \& Fallon, R. J. (1994). Detection of mip gene by PCR for diagnosis of Legionnaires' disease. J Clin Microbiol 32, 3068-3069.

Lindsay, D. S. J., Abraham, W. H., Findlay, W., Christie, P., Johnston, F. \& Edwards, G. F. S. (2004). Laboratory diagnosis of legionnaires' disease due to Legionella pneumophila serogroup 1: comparison of phenotypic and genotypic methods. J Med Microbiol 53, 183-187.

Matsiota-Bernard, P., Waser, S. \& Vrioni, G. (2000). Detection of Legionella pneumophila DNA in urine and serum samples from patients with pneumonia. Clin Microbiol Infect 6, 223-225.

Murdoch, D. R. (2003). Diagnosis of Legionella infection. Clin Infect Dis 36, 64-69.

Murdoch, D. R. \& Chambers, S. T. (2000). Detection of Legionella DNA in peripheral leukocytes, serum, and urine from a patient with pneumonia caused by Legionella dumoffi. Clin Infect Dis 30, 382-383.

Murdoch, D. R., Walford, E. J., Jennings, L. C., Light, G. J., Schousboe, M. I., Chereshsky, A. Y., Chambers, S. T. \& Town, G. I. (1996). Use of the polymerase chain reaction to detect Legionella DNA in urine and serum samples from patients with pneumonia. Clin Infect Dis 23, 475-480.

Murdoch, D. R., Jennings, L. C., Light, G. J. \& Chambers, S. T. (1999). Detection of Legionella DNA in guinea pig peripheral leukocytes, urine and plasma by the polymerase chain reaction. Eur J Clin Microbiol Infect Dis 18, 445-447.

Steele, T. W., Moore, C. Y. \& Sangster, N. (1990). Distribution of Legionella longbeachae serogroup 1 and other legionellae in potting soils in Australia. Appl Environ Microbiol 56, 2984-2988.

Yu, V. L., Plouffe, J. F., Pastoris, M. C. \& 8 other authors (2002). Distribution of Legionella species and serogroups isolated by culture in patients with sporadic community-acquired legionellosis: an international collaborative study. J Infect Dis 186, 127-128.

Yzerman, E. P. F., den Boer, J. W., Lettinga, K. D., Schellekens, J., Dankert, J. \& Peeters, M. (2002). Sensitivity of three urinary antigen tests associated with clinical severity in a large outbreak of Legionnaires' disease in The Netherlands. J Clin Microbiol 40, 3232-3236. 